\title{
European Hazelnut Oil
}

National Cancer Institute

\section{Source}

National Cancer Institute. European Hazelnut Oil. NCI Thesaurus. Code C107306.

The oil extracted from the nuts of Corylus avellana. Hazelnut oil is used as a food ingredient and flavoring. 